\title{
ピッチとコイル径が変化するコイルばねの セッチングによる高さ変化の推定
}

Inference of Change of Height due to Pre-setting in Coil Springs with Varied Pitch and Coil Diameter

下関 正義・佐藤 基行

Masayoshi SHIMOSEKI $\cdot$ Motoyuki SATO

\section{1. 緒言}

一般の円筒コイルばねのセッチングに関する解析とし て，弾完全塑性を仮定した文献 1) がある.しかし、コ イルばねのセッチングは, 密着高さによって圧縮量に制 限があるため, トーションバーのようにあまり大きな塑 性加工を期待することはできない，つまり弾性限をわず かに越えたあたりでの加工が行なわれているととにな り，その場合に材料を弾完全塑性体としてとらえるの は，いささか無謀である．そこでこの材料モデルを弾線 形硬化塑性体 ${ }^{2}$ に修正して解析し直したあのとして文献 3）があり，等ピッチ円筒ばねには充分適用できる.

しかし，現在特に自動車用懸架ばねにおいて，スペー ス上,コイル径を絞ったばねや騒音の問題からピッチを 変えたばねが要求されて扔り，すでに量産体制に入って いる.とのように複雑な形状のばねは勘と経験により見 越し高さをつけるという試行錯誤にたよらざるをえない のが実状である.

そこで本報告の主目的はピッチとコイル径が場所によ って変化するようなコイルばねにも適用できるように従 来の解析結果をさらに発展させることにある.

つまり,コイルばねを有限要素に分割し，その要素に 関し従来の解析結果 ${ }^{33}$ を適用する. 乙の場合, 多次元量 を取扱うことになるのでマトリックス法を使用する.

以上の基礎式をむとに，ばね諸元などを与えた具体例 の数值計算を行ない結果を実験值と比較したととろ，か なり良い精度で高さの変化量を推定できることが確認さ れたので，乙てに報告する。

\section{2. 理論解析}

セッチング後の完成品の形状は, 図面によって部分的 な離散量で与えられており，一つの数式によっててれを 記述するのは不可能である. したがって，とてでの解析 は離散量をそのまま取扱うような方法に依らざるを得な い，そこで，まずコイルばねをいくつかの要素に分制す る. その際各要素内でコイル径ならびにピッチを一定と
みなし得るに十分な分割数とする.

\section{1 仮定}

解析をするに当って次の仮定を扔く，

（a）コイルばねの高さ変化は未修正応力に依存する あのとする.

（b）加工硬化はひずみに対して直線的に増加するす のとする.

（c）塑性変形後も横弹性係数は, 加荷, 減荷によら ず一定であるあのとする.

（d）軸荷重はコイル中心軸上に㗢くものとする.

2.2 記号

解析に用いる主な記号は次のとおりである.

$d:$ 材料直径 $(\mathrm{mm})$

$d_{e}:$ 材料の弾性部分の直径 $(\mathrm{mm})$

$G:$ 横弾性係数 $\left(\mathrm{kgf} / \mathrm{mm}^{2}\right)$

$\tau_{e}:$ ねじり弾性限 $\left(\mathrm{kgf} / \mathrm{mm}^{2}\right)$

$T:$ 丸棒に加わるトルク (kgf-mm)

$T_{e}$ : 丸棒の弾性限界時トルク $(\mathrm{kgf}-\mathrm{mm})$

$\theta:$ 比权じり角 $\left(\mathrm{mm}^{-1}\right)$

$\theta_{e}$ : 弾性限界時比䄪じり角 $\left(\mathrm{mm}^{-1}\right)$

$P:$ コイルばねに加わる軸荷重 $(\mathrm{kgf})$

$\boldsymbol{H}$ : 各要素に拈ける高さを成分にあつ対角マトリッ クス $(\mathrm{mm})$

$\boldsymbol{D}:$ 各要素におけるコイル平均径を成分にもつ対角 マトリックス $(\mathrm{mm})$

$\boldsymbol{N}$ : 各要素に扔ける巻数を成分にあつ対角マトリッ クス (-)

$\boldsymbol{P}$ : 各要素に作用する軸荷重を成分にあつ対角マト リックス (kgf)

(注) 上添字*は未接着部, ’は接着部を示す。

下添字Ｉはセッチング前， IIはセッチング時， IIIはセッチング後を示す.

\section{3 構成方程式}

丸棒の弾塑性ねじりではトルクと比ねじり角との関係 式は, 弾線形硬化塑性体を仮定した場合, 次式)で与え られる。 


$$
K=\frac{4}{3}\left(1-\frac{1}{\alpha}\right)\left(1-\frac{1}{\beta^{3}}\right)+\frac{1}{\beta^{3}}+\frac{\beta}{\alpha}\left(1-\frac{1}{\beta^{4}}\right) \cdots
$$

ただし

$\alpha$ : 硬さの関数として与えられるスカラー量 ${ }^{3)}$

$\beta=\frac{d}{d_{e}}=\frac{\theta}{\theta_{e}}$

ところが，ここで解析を行なおうとしているばねに関 しては各位置によって $\beta$ ，したがって $K$ が異なるため， てれらの諸量を多次元化しておく必要がある.

また，ばねのセッチングによる見越量を求めるために は式(1),(2) より最終的に各コイル要素の高さ変化量 を求める必要がある，そてで本節に倣いては，式(1), (2)を多次元化し各コイル要素の高さで表わした式に書 き改める.

まず，高さに関する 3 つのマトリックスを定義する.

$$
\begin{aligned}
& \boldsymbol{H}_{\mathrm{I}}=\operatorname{diag} .\left\lfloor h_{\mathrm{I} 1}, h_{\mathrm{I} 2}, \cdots, h_{\mathrm{I} n}\right\rfloor \\
& \boldsymbol{H}_{\mathrm{II}}=\operatorname{diag} .\left\lfloor h_{\mathrm{II} 1}, h_{\mathrm{II} 2}, \cdots, h_{\mathrm{II} n}\right\rfloor \\
& \boldsymbol{H}_{\mathrm{III}}=\operatorname{diag} .\left\lfloor h_{\mathrm{III} 1}, h_{\mathrm{III} 2}, \cdots, h_{\mathrm{III} n}\right\rfloor
\end{aligned}
$$

ただし, diag. : 対角マトリックス

なお，下添字 2 番目の数字は分割した各要素の番号を 表わす.

また，高さと同様にコイル平均径む各位置によって異 なるため, 各部による対角マトリックスとして次のよう に定義する.

$$
\boldsymbol{D}=\operatorname{diag} .\left\lfloor D_{1}, D_{2}, \cdots, D_{n}\right\rfloor
$$

また，各要素に分割した巻数の大きさについても次の ように定義する。

$$
\boldsymbol{N}=\operatorname{diag} .\left\lfloor N_{1}, N_{2}, \cdots, N_{n}\right\rfloor
$$

以上の定義より，各位置に打ける $\beta, K$ の值を求めれ ば,

$$
\begin{aligned}
& \boldsymbol{\beta}=\frac{G d}{\pi \tau_{e}} \boldsymbol{N}^{-1} \boldsymbol{D}^{-2}\left(\boldsymbol{H}_{\mathrm{I}}-\boldsymbol{H}_{\mathrm{II}}\right) \cdots \cdots \ldots \ldots \ldots \ldots \ldots . . . \\
& \boldsymbol{K}=\frac{4}{3}\left(1-\frac{1}{\alpha}\right) \boldsymbol{I}-\frac{1}{3}\left(1-\frac{1}{\alpha}\right) \boldsymbol{\beta}^{-3}+\frac{1}{\alpha} \boldsymbol{\beta}
\end{aligned}
$$

ただし，I：単位マトリックス となる。

\section{4 基礎式の誘導}

前節における解析は, 各要素でのたわみと荷重に関す る構成方程式を材料非線形問題としてとらえたものであ る.

ところが今解析しようとしているような複雑な形状の ばねでは, 材料非線形以外に, 幾何学的非線形む考慮し ておく必要がある.つまり, 弾性領域での変形む, 図 1 の $\mathrm{a}-\mathrm{b}$ 間のでとく非線形となる．乙れは各部における接 着荷重が異なることに起因しており，等ピッチ円筒コイ ルばねの場合には考慮する必要がないものであった（図 $\left.1 \mathrm{a}^{\prime}-\mathrm{b}\right)$.

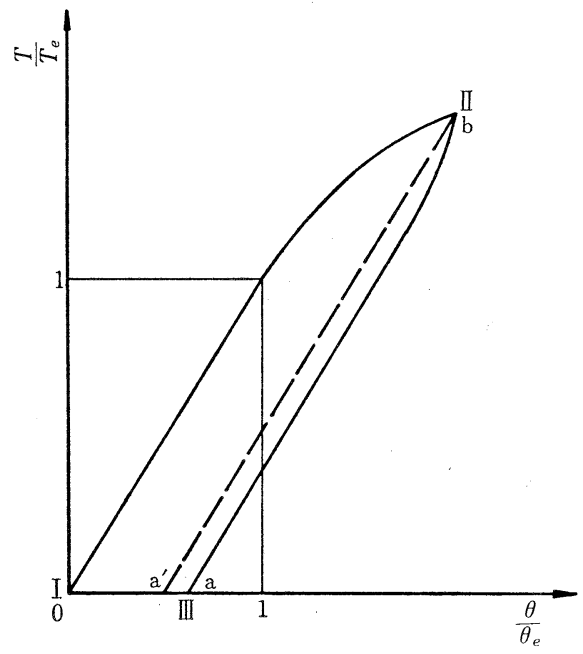

図 $1 T / T_{e} \sim \theta / \theta_{e}$ 線図

そこで，ての幾何学的非線形性を考慮しながら式 (4) をさらに発展させ，最終的にはセッチング後の形状と， セッチング高さを与えて，巻き上り時のばねのピッチを 求めることとして, 以下の解析を進めていく.

つまり与えられるデータは

$\boldsymbol{H}_{\mathrm{III}}, \operatorname{tr} \boldsymbol{H}_{\mathrm{III}}, \operatorname{tr} \boldsymbol{H}_{\mathrm{II}}$

ただし, $\operatorname{tr}$ ：主対角成分の和

であり，これらのデータをあとにセッチング荷重を求め る。

ここで, 各要素のたわみ性を次の対角マトリックスで 定義する.

$$
\boldsymbol{F}=\text { diag. }\left\lfloor F_{1}, F_{2}, \cdots, F_{n}\right\rfloor
$$

また，セッチング時にコイル間の接着はないもの，つ まり，ばね特性は線形と考える.

ばね全体を考えれば，次のようになる。

$$
\operatorname{tr} \boldsymbol{H}_{\mathrm{III}}-\operatorname{tr} \boldsymbol{H}_{\mathrm{II}}=P \times \operatorname{tr} \boldsymbol{F}
$$

$\therefore P=\frac{\operatorname{tr} \boldsymbol{H}_{\mathrm{III}}-\operatorname{tr} \boldsymbol{H}_{\mathrm{II}}}{\operatorname{tr} \boldsymbol{F}}$

また，各要素に着目すれば

$$
\begin{aligned}
& \boldsymbol{H}_{\mathrm{III}}-\boldsymbol{H}_{\mathrm{II}}=P \boldsymbol{F} . \\
& \boldsymbol{H}_{\mathrm{II}}=\boldsymbol{H}_{\mathrm{III}}-P \boldsymbol{F} .
\end{aligned}
$$

となり式(6)より

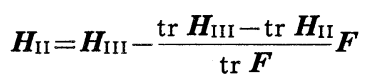

となり， $\boldsymbol{H}_{\mathrm{II}}$ が求まる.

以上のコイル間の接着はないと仮定した場合のたわみ 量と実際の各要素に㧍ける接着までのたわみ得る量とを 比較する.

ここで各要素における接着時の高さを次のように定義 する.

$$
\boldsymbol{H}_{s}=\text { diag. }\left\lfloor h_{s 1}, h_{s 2}, \cdots, h_{s n}\right\rfloor
$$


また，各要素におけるたわみ得る量を $\boldsymbol{H}_{\mathrm{III}}, \boldsymbol{H}_{s}$ を使っ $\tau$,

$$
\Delta \boldsymbol{H}=\boldsymbol{H}_{\mathrm{III}}-\boldsymbol{H}_{s}
$$

と定義する。

ここで次式を導入し

$$
\left[\boldsymbol{H}_{\mathrm{III}}-\boldsymbol{H}_{\mathrm{II}}\right]-\Delta \boldsymbol{H}
$$

各要素に関して式(11)の正負の判別を行なう.

あし，ここで式(11)が正になる要素があれば，その要 素は前述のように，セッチング時にコイル間の接着なし と仮定した時のセッチング荷重 $P$ 以前に接着することに

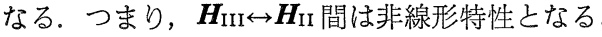

それでは，ととで $n$ 個の要素のうち 1〜 $k$ は接着, $(k+1) \sim n$ は未接着とするならば,

$$
P * \boldsymbol{F}^{*}=\boldsymbol{H}_{\mathrm{III}} *-\boldsymbol{H}_{\mathrm{II}} *
$$

ただし*は $(k+1) \sim n$ に適用

$$
\boldsymbol{P}^{\prime} \boldsymbol{F}^{\prime}=\Delta \boldsymbol{H}^{\prime}
$$

ただし'は $1 〜 k$ に適用 となる。

ここで $\boldsymbol{P}^{\prime}$ は 1〜 $k$ の各要素における接着荷重である. また,ここで未接着要素に注目すれば

$$
\begin{aligned}
P^{*} & =\frac{\operatorname{tr} \boldsymbol{H}_{\mathrm{III}}{ }^{*}-\operatorname{tr} \boldsymbol{H}_{\mathrm{II}}^{*}}{\operatorname{tr} \boldsymbol{F}^{*}} \\
& =\frac{\left(\operatorname{tr} \boldsymbol{H}_{\mathrm{III}}-\operatorname{tr} \boldsymbol{H}_{\mathrm{III}}\right)-\left(\operatorname{tr} \boldsymbol{H}_{\mathrm{II}}-\operatorname{tr} \boldsymbol{H}_{\mathrm{II}}{ }^{\prime}\right)}{\operatorname{tr} \boldsymbol{F}^{*}} \\
& =\frac{\left(\operatorname{tr} \boldsymbol{H}_{\mathrm{III}}-\operatorname{tr} \boldsymbol{H}_{\mathrm{II}}\right)-\left(\operatorname{tr} \boldsymbol{H}_{\mathrm{III}}{ }^{\prime} \operatorname{tr} \boldsymbol{H}_{\mathrm{II}}\right)}{\operatorname{tr} \boldsymbol{F}^{*}}
\end{aligned}
$$

式(14)を式(12)に代入するととによって

$\therefore \boldsymbol{H}_{\mathrm{II}}{ }^{*}=\boldsymbol{H}_{\mathrm{III}}{ }^{*}-\frac{\left(\operatorname{tr} \boldsymbol{H}_{\mathrm{III}}-\operatorname{tr} \boldsymbol{H}_{\mathrm{II}}\right)-\left(\operatorname{tr} \boldsymbol{H}_{\mathrm{III}}{ }^{\prime}-\operatorname{tr} \boldsymbol{H}_{\mathrm{II}}\right)}{\operatorname{tr} \boldsymbol{F}^{*}} \boldsymbol{F}$

が与えられる．以後はこれの繰返し計算になり

$$
\boldsymbol{H}_{\mathrm{III}} *-\boldsymbol{H}_{\mathrm{II}} *-\Delta \boldsymbol{H}^{*}
$$

すべての要素で(16)式が負になるまで繰返す．とのよう にして得られた結果を用い，式(14)よりセッチング荷重 $P *$ を求めることができる．次に弾塑性の臨界点を捜 す．セッチング状態で各要素に作用する力は，未接着部 と接着部によって異なる. 未接着部に関しては，セッチ ング時の外力 $P^{*}$ が，そのまま作用していることにな る. 一方，接着部に関しては，各位置にたわみ性と線間 すきまによって定まる接着荷重が負荷されていることに なる，そこで弾塑性域の臨界点はそれぞれ次式で与えら れる.

$$
\begin{aligned}
& D_{c r} *=\frac{\pi \tau_{e} d^{3}}{8 P^{*}} \quad \text { (未接着部) } \cdots . \\
& \boldsymbol{D}_{c r} *=\frac{\pi \tau_{e} d^{3}}{8}\left(\boldsymbol{P}^{\prime}\right)^{-1} \quad \text { (接着部) }
\end{aligned}
$$

未接着部に関しては，式(17)により $\left(\boldsymbol{D}^{*}\right) i<D_{c r} *$ なら
ば弾性域であり， $(\boldsymbol{D} *)_{i}>D_{c r} *$ ならば塑性域ということ になる．また接着部に関しては式(18)と $\boldsymbol{D}$ との対角成 分を比較することによって，同様な判別をすることがで きる、すなわち各要素は次のグループのいずれかに属す る。

i ) $\left(\boldsymbol{D}^{\prime}\right)_{i}<\left(\boldsymbol{D}_{c r}\right)_{i}$ (接着部で弾性域)

ii ) $\left(\boldsymbol{D}^{*}\right)_{i}<D_{c r} *$ (未接着部で弾性域

iii ) $\left(\boldsymbol{D}^{\prime}\right)_{i}>\left(\boldsymbol{D}_{c r^{\prime}}\right)_{i}$ (接着部で塑性域)

iv ) $(\boldsymbol{D} *)_{i}>D_{c r} *$ （未接着部で塑性域）

上記の 4 グループに関して各々の要素における $\boldsymbol{H}_{\mathrm{I}}$ を 求める.

i ), ii ) のグループ

このグループは接着，未接着にかかわらず弾性域であ るから

$$
\begin{aligned}
& \boldsymbol{H}_{\mathrm{I}}^{\prime}=\boldsymbol{H}_{\mathrm{III}}{ }^{\prime} \\
& \boldsymbol{H}_{\mathrm{I}} *=\boldsymbol{H}_{\mathrm{III}} *
\end{aligned}
$$

である。

iii) グループ

このグループは塑性域であり，接着しているので $\boldsymbol{P}^{\prime}$ で評価する， $\boldsymbol{P}^{\prime}$ は式(13)より求まり，乙の $\boldsymbol{P}^{\prime}$ を使え ば,

$$
\boldsymbol{K}^{\prime}=\frac{\boldsymbol{T}}{T_{e}}=\frac{1}{2 T_{e}} \boldsymbol{D}^{\prime} \boldsymbol{P}^{\prime}
$$

となる．式(1)を次のように書き直し

$$
\frac{1}{\alpha} \boldsymbol{\beta}^{\prime 4}+\left\{\frac{4}{3}\left(1-\frac{1}{\alpha}\right)-\boldsymbol{K}^{\prime}\right\} \boldsymbol{\beta}^{\prime 3}-\frac{\boldsymbol{I}}{3}\left(1-\frac{1}{\alpha}\right)=0
$$

ここに式(25)を代入すれば， $\boldsymbol{\beta}^{\prime}$ が $\boldsymbol{P}^{\prime}$ の関数として得ら れ，最終的に，

$$
\boldsymbol{H}_{\mathrm{I}}^{\prime}=2 T_{e} \boldsymbol{\beta}^{\prime}\left(\boldsymbol{D}^{\prime} \boldsymbol{P}^{\prime}\right)^{-1} \Delta \boldsymbol{H}^{\prime}+\boldsymbol{H}_{\mathrm{II}}
$$

となる。

iv）のグループ

このグループは塑性域の未接着であるからスカラ一量 P*によって評価できる.

$$
\boldsymbol{K} *=\frac{1}{2 T_{e}} P * \boldsymbol{D} *
$$

式(1)を式(26)と同様に次のように書き直し

$$
\frac{1}{\alpha} \beta^{* 4}+\left\{\frac{4}{3}\left(1-\frac{1}{\alpha}\right)-\boldsymbol{K}^{*}\right\} \boldsymbol{\beta}^{* 3}-\frac{\boldsymbol{I}}{3}\left(1-\frac{1}{\alpha}\right)=0
$$

ここに式(28)を代入すれば式(27)と同様に

$$
\boldsymbol{H}_{\mathrm{I}} *=2 T_{e} \boldsymbol{\beta}^{*}\left(\boldsymbol{D}^{*} P^{*}\right)^{-1}\left(\boldsymbol{H}_{\mathrm{III}} *-\boldsymbol{H}_{\mathrm{II}} *\right)+\boldsymbol{H}_{\mathrm{II}} * \ldots
$$

となる。

以上の 4 グループにおける，各要素の $\boldsymbol{H}_{\mathrm{I}^{\prime}}{ }, \boldsymbol{H}_{\mathrm{I}} *$ を合 成すれば,

$$
\operatorname{tr} \boldsymbol{H}_{\mathrm{I}}=\operatorname{tr} \boldsymbol{H}_{\mathrm{I}}{ }^{\prime}+\operatorname{tr} \boldsymbol{H}_{\mathrm{I}}{ }^{*}
$$

となり,ばね全体の巻き上り高さが得られる。 


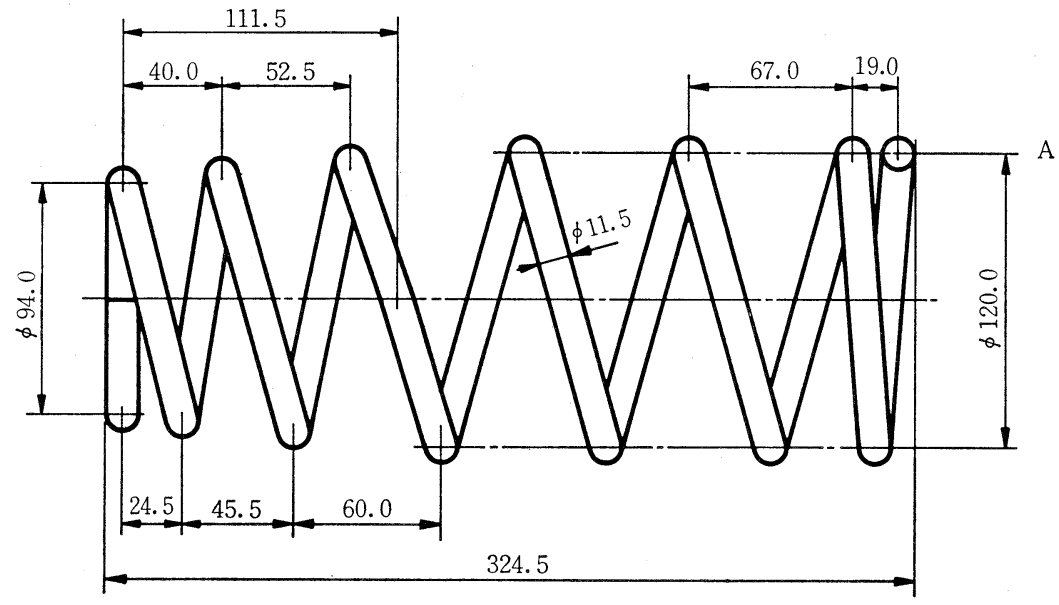

図 2 ばね概略図

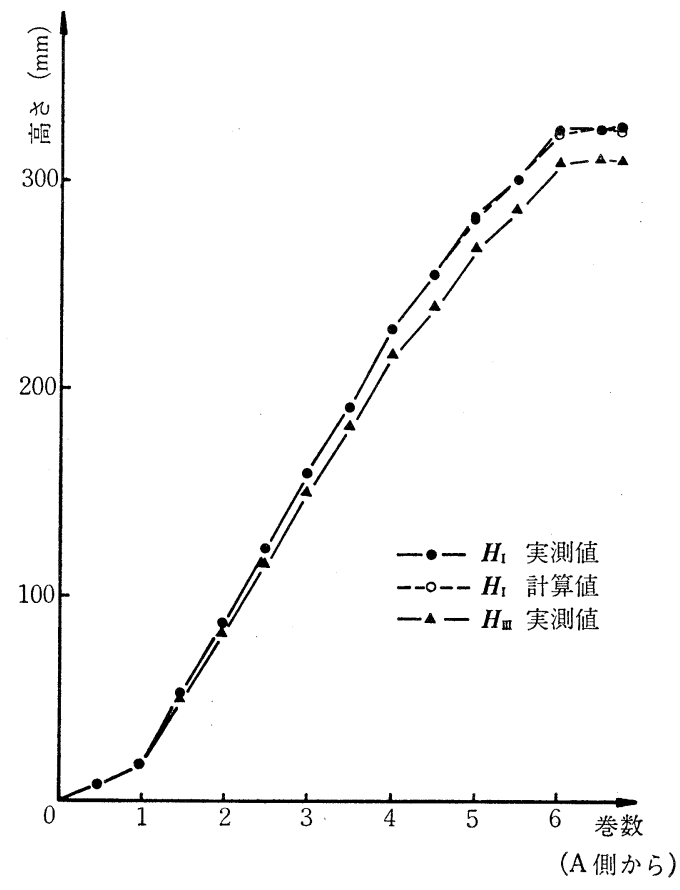

図 3 展開曲線

\section{3. 具体的検討}

2 章に得られた諸式を用いて，具体的な数值計算を行 ない，実測值と照合してみることにする。

対象とするばねは，図 2 のような完成形状とする。 ま たセッチング時の高さ $\operatorname{tr} \boldsymbol{H}_{\mathrm{II}}$ は

$$
\operatorname{tr} \boldsymbol{H}_{\mathrm{II}}=123 \quad(\mathrm{~mm})
$$

とする. 次に各要素は $1 / 8$ 巻の大きさで分割すること とし, 図2 より得られる $\boldsymbol{H}_{\mathrm{III}}, \boldsymbol{D}$ の情報を使い $P^{*}, \boldsymbol{P}^{\prime}$ を求める. また, $\tau_{e}=0.16 H_{B}$ より ${ }^{3)}, \tau_{e}=68.64(\mathrm{kgf} /$ $\left.\mathrm{mm}^{2}\right)$ とすれば, 式(19) (20) のグループ i ), ii ) は存在

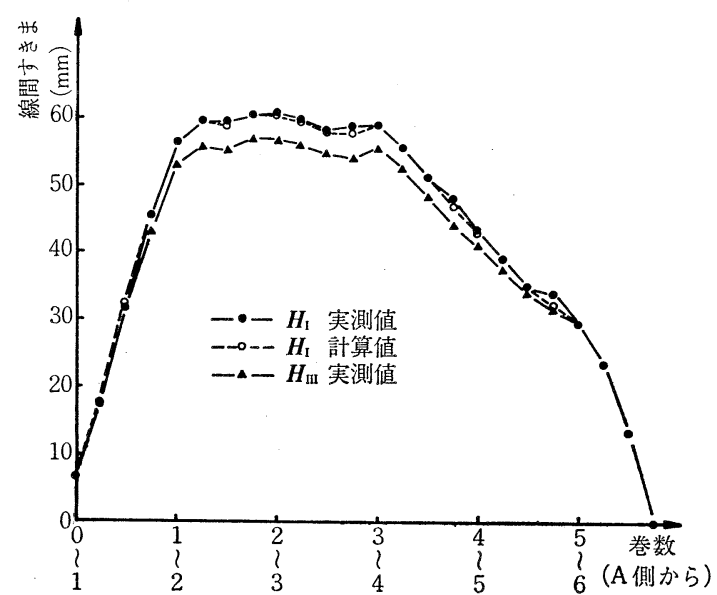

図 4

せず全域にわたり塑性変形していることになる．したが ってばねはグループ Iili)，（iv）に分類され，さらに文献 3) より

$$
\alpha=\left(-4.17 \times 10^{-3}\right) H_{B}+3.707
$$

であるから， $\alpha=1.93$ とし，式(27) (30)を適用すれば, 巻き上り形状 $\boldsymbol{H}_{\mathrm{I}}$ が算出される. 結果は図 3,4 亿示す通 りであり，実測值と比較して実用上十分な精度とみなし てよいととがわかる，なお図中， $\boldsymbol{H}_{\mathrm{I}}$ 計算值（。印）と $\boldsymbol{H}_{\mathrm{I}}$ 実測值（・印）とが若干ずれている籄所は，コイル 径が所定の值に成形されていないためと思われる.

\section{4. 結言}

ピッチならびにコイル平均径が場所によって変化する ようなコイルばねに関して, 各位置でのセッチングによ る高さ変化量を決定するような理論式は存在しない.

そこで本報告において，乙の解析を行ない，マトリッ クス法によっててれを定式化した. マトリックス法を使 
用した理由は，数式がはん雑になるため，てれを簡明に 表示させることにあるが，乙れに加えて実用的にはコン ピュータ処理の簡便さも無視し得ないメリットであると 考えている.

実際には,

1. コイルばねを有限要素に分割する

2. 各要素に関して従来の解析 ${ }^{3}$ を適用する

3. 種々の状態を考慮し合成する

という解析を行なった．特に3. については従来の解析 にはない, 幾何学的非線形性を考慮している.

また, 解析結果を用いて, 具体的な数值計算を行ない,
実測値と比較したところ，かなり良い精度で近似できる ことが確認された。

\section{参考文献}

1) 水野: “ば称の製造・設計の材料力学 (4)”機械の研究 No. 24, Vol. 8 (1970) p. 64, 養賢堂.

2）国尾: “固体力学の基礎” p. 205, 培風館.

3）下関, 押田：“コイルばねのセッチングによる高さ変化量 そついでばね論文集, No. 20 (1975) p. 70.

4) A.M. WAHL: "Mechanical Springs" p. 260 McGRAW-HILL. 